\title{
Micro-Computed Tomographic Applications in the Geological Sciences
}

Tara Selly and James Schiffbauer

Affiliation 1, United States

X-ray computed tomographic microscopy (CT) reached the 50-year anniversary of being commercially available this year. While this technology was originally manufactured with the medical community in mind, geologists and paleontologists were quick to take advantage of the emerging technique and have continued to revolutionize its applications in the field. One of the first studies to do so, less than a decade after the technology became available, analyzed the cross-sectional geometry of intact fossil long bones of extinct primates and directly compared them to modern humans (Jungers and Minns, 1979). This study demonstrated the utility of CT in paleontological applications, and through technological advances and a new generation of imaging techniques, it continues to present new horizons by providing non-destructive, three-dimensional, external and internal views of a vast diversity of geologic samples. Owing to the non-invasive nature of CT, rare or museum quality samples can be examined without destruction; and with technological advancements over the last 50 years, micro-computed $\mathrm{x}$-ray tomography $(\mu \mathrm{CT})$ has unlocked even higher spatial resolution (to the sub-micrometer scale), making it an increasingly valuable tool in the new digital age. Improvements in technology, ease of use, and expanding access to such instruments have established $\mu \mathrm{CT}$ as a cornerstone in the world of digital/virtual geology. In this presentation, we use a variety of examples from work conducted at the newly established Mizzo $\mu$ X Core Facility for X-ray Microanalysis at the University of Missouri's Department of Geological Sciences to provide a brief tour of historical CT applications, discuss recent advancements in the technology, and illustrate benefits of combined, multi-technique approaches in analyses. Specifically, both published and unpublished rock, mineral, fossil, and biological materials will be used to illustrate the benefits, ambitions, and pitfalls of CT-based analyses in geologic research.

A

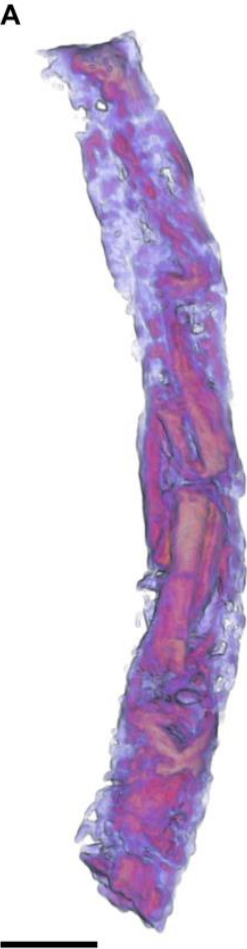

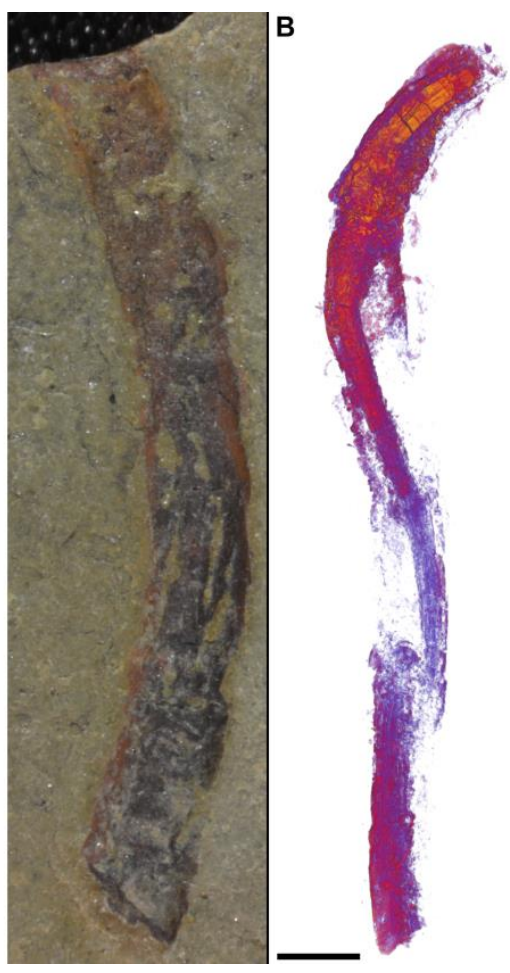

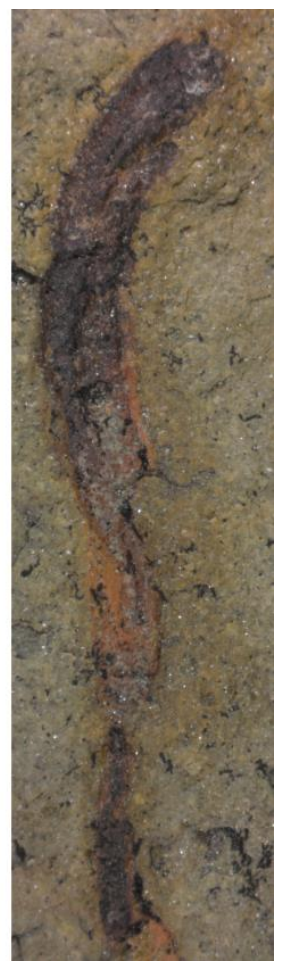

Figure 1. 3D volume-render using contrast filters to accentuate external tube morphology (left image per frame) of pyritized soft tissue fossil cloudinomorphs (right image per frame) from the Wood Canyon 
Formation, NV. Examples show (A) kinking and folding and (B) partial degradation/fragmentation. All scales $=2 \mathrm{~mm}$. Figure revised from Schiffbauer et al., 2020

\section{References}

[1] Jungers, W. L., \& Minns, R. J. 1979. Computed tomography and biomechanical analysis of fossil long bones. American journal of physical anthropology, 50(2), 285-290.

[2] Schiffbauer, J. D., Selly, T., Jacquet, S. M., Merz, R. A., Nelson, L. L., Strange, M. A., ... \& Smith, E. F. 2020. Discovery of bilaterian-type through-guts in cloudinomorphs from the terminal Ediacaran Period. Nature communications, 11(1), 1-12. 